\title{
Effect of Therapeutic Dose of Vitamin D on Serum Adiponectin and Glycemia in Vitamin D-Insufficient or Deficient Type 2 Diabetic Patients
}

\author{
Nima Baziar ${ }^{1}$; Kurosh Jafarian ${ }^{1}$; Zhaleh Shadman ${ }^{2}$; Mostafa Qorbani ${ }^{3,4}$; Mohsen Khoshniat \\ Nikoo $^{2, *} ;$ Mahshid Abd Mishani ${ }^{2}$ \\ ${ }^{1}$ Department of Clinical Nutrition and Dietetics Therapy, Faculty of Nutrition Sciences and Food Technology, Tehran University of Medical Sciences, Tehran, IR Iran \\ ${ }^{2}$ Endocrinology and Metabolism Research Center, Endocrinology and Metabolism Clinical Sciences Institute, Tehran University of Medical Sciences, Tehran, IR Iran \\ ${ }^{3}$ Department of Community Medicine, Alborz University of Medical Sciences, Karaj, IR Iran \\ ${ }^{4}$ Non Communicable Diseases Research Center, Endocrinology and Metabolism Population Sciences Institute, Tehran University of Medical Sciences, Tehran, IR Iran \\ *Corresponding Author: Mohsen Khoshniat Nikoo, IR Iran. Tel: +98-2188220094; Ext: 5; Fax: +98-2188220052, E-mail: khoshniatmohsen@yahoo.com
}

Received: June 22, 2014; Revised: August 16, 2014; Accepted: August 30, 2014

\begin{abstract}
Background: Lower vitamin D status has been reported in diabetic patients. Serum 25-hydroxyvitamin D and adiponectin were inversely associated with type 2 diabetes and insulin resistance. Vitamin D may involve in regulation of the adiponectin levels, which is directly related to insulin sensitivity.

Objectives:The aim of this study was to investigate the effect of therapeutic dose of vitamin D on serum adiponectin and insulin resistance in vitamin D-insufficient or deficient type 2 diabetic patients.

Materials and Methods: This double-blind, randomized, clinical trial was conducted on 81 type 2 diabetic patients with vitamin D level of $10-30 \mathrm{ng} / \mathrm{mL}$. Intervention was $50000 \mathrm{IU}$ vitamin D or placebo once a week for 8 weeks. At the beginning and end of the study, blood samples were collected after 12 hours of fasting and serum glucose, insulin, 25 -hydroxyvitamin D, and adiponectin were measured. Insulin resistance was calculated by homeostasis model assessment (HOMA-IR).

Results: After 8-week intervention, serum 25-hydroxyvitamin D significantly increased and reached the normal levels in patients receiving vitamin $\mathrm{D}(\mathrm{P}<0.001)$ and the levels of fasting serum glucose, insulin, and HOMA-IR were significantly decreased $(\mathrm{P}=0.04,0.02 \mathrm{and} 0.007$, respectively). No significant changes were observed in these levels in the placebo group. Significant differences were observed in mean changes in the above-mentioned variables between the two groups $(\mathrm{P}=0.01,0.04$ and 0.006 , respectively). No significant changes were found in serum adiponectin in the vitamin $\mathrm{D}$ and placebo groups $(\mathrm{P}=0.83)$.

Conclusions: Therapeutic dose of vitamin D can improve vitamin D status and glycemic indicators. But it seems that an 8-week intervention period was not sufficient to reveal the possible effects of vitamin $\mathrm{D}$ on serum adiponectin levels.
\end{abstract}

Keywords:Diabetes Mellitus; Vitamin D; Insulin Resistance; Adiponectin

\section{Background}

The association between the several non-skeletal diseases and vitamin D deficiency has been recently reported $(1,2)$. Some risk factors of vitamin D deficiency and type 2 diabetes are similar (e.g. ethnicity, obesity, age and low physical activity level). A low level of vitamin D status has been reported in diabetic patients (1, 3-5). Vitamin D may be involved in the pathways of insulin production, secretion, and possibly insulin signaling in insulin-sensitive tissues (6). It may be effective in reducing the risk of type 2 diabetes $(4,7,8)$ and its management $(3,6)$. Vitamin D deficiency was associated with insulin resistance $(4,7,9$, 10) and considered as a risk factor for type 2 diabetes (2, 7 , 10). Adiponectin is one of the suggested mechanisms by which vitamin D may affect insulin sensitivity $(5,11)$ and epidemiological studies have shown that adiponectin is inversely associated with obesity, insulin resistance, diabetes, metabolic syndrome, cardiovascular disease and hypertension (12-21). In comparison to healthy people, the lower plasma concentrations of adiponectin have been reported in type 2 diabetic patients and obese people $(7,22,23)$. Thiazolidinediones-induced improvement in insulin sensitivity may be related to an increase in serum adiponectin (23).

Reported positive association between vitamin $\mathrm{D}$ and adiponectin in cross-sectional studies $(5,7,21,24,25)$ may be arise from that vitamin $D$ may affect serum adiponectin through increased adiponectin gene expression (5) or renin-angiotensinogen system (11). Given this relationship and since vitamin D status, as well as adiponectin, is inversely associated with insulin resistance and cardiovascular diseases (24-26), it can be suggested a possible role of the adiponectin -dependent vitamin D effect in decreasing insulin resistance and cardiovascular diseases. Thus, it is important to evaluate the effect of vitamin D

Copyright ( ) 2014, Iranian Red Crescent Medical Journal; Published by Kowsar. This is an open-access article distributed under the terms of the Creative Commons Attribution-NonCommercial 4.0 International License (http://creativecommons.org/licenses/by-nc/4.0/) which permits copy and redistribute the material just in noncommercial usages, provided the original work is properly cited. 
supplementation on adiponectin concentration and illustrate whether vitamin D may improve the glycemic indicators through adiponectin. Vitamin D supplementation alone, or in combination with calcium has shown conflicting results in prevention or management of type 2 diabetes $(6,27)$. These discrepancies may arise from lack of coordination in methodological design, supplementation dosage, duration, baseline body vitamin status and etc.

Since adiponectin is associated with a better glycemic control and other metabolic indicators, identifying the causes of deficiency and its enhancing factors may be useful in the management of diabetes and metabolic syndrome. However, only two interventional studies have been conducted to determine the effects of vitamin D supplementation on serum adiponectin and subsequent blood glucose $(10,28)$.

\section{Objectives}

Regarding the high prevalence of diabetes (29) and vitamin D deficiency (30) in Iran and since vitamin D deficiency may increase insulin resistance through low adiponectin levels, the aim of this study was to investigate the effect of therapeutic dose of vitamin D (a single dose of $50000 \mathrm{IU} /$ week for 8 weeks) on serum adiponectin and insulin resistance in vitamin D-insufficient or deficient type 2 diabetic patients.

\section{Materials and Methods}

This double-blind, randomized, clinical trial was approved by the ethic committee of endocrinology and metabolism research center, Tehran University of Medical Sciences (00220) and was conducted during DecemberMarch 2012 at the diabetes and metabolic disease clinic of endocrinology and metabolism research center, Tehran University of Medical Sciences, Tehran, Iran.

\subsection{Subjects}

Sample size was determined according to variable HOMA-IR of Al-Daghri et al. clinical trial (25) considering $\alpha=0.05$ and $\beta=0.02$, the mean differences for vitamin $\mathrm{D}$ and placebo groups were $0.04 \pm 0.06$ and $0.01 \pm 0.03$, respectively. By the possibility of $10 \%$ for sample missing, the required sample size per group was determined 44 cases.

Using medical documents, 105 type 2 diabetic patients controlled by oral glucose-lowering agents were invited to participate in the study and 98 patients were selected according to document-based inclusion criteria. Serum 25-hydroxyvitamin D, aspartate transaminase, alanine transaminase, creatinine, blood urea nitrogen and glycated hemoglobin were measured and nine patients were excluded from the study because their vitamin D status was not within the vitamin D range of the study and also two cases were excluded due to HbA1c more than $8 \%$. Overall, 87 patients were recruited the trial and allocated into two groups through sex-stratified randomization (43 receiving vitamin D and 44 receiving placebo)(Figure 1). Inclusion criteria were diagnosed type 2 diabetes mellitus $>$ one year and $>30$ years old, aged $31-65$, body mass index (BMI) $>25$ and $<30 \mathrm{~kg} / \mathrm{m}^{2}$, serum 25hydroxyvitamin D 10-30 ng/mL, glycated hemoglobin (HbA1c) $<8 \%$, no alcohol consumption and smoking, insulin therapy, consuming thiazolidinediones, pregnancy or menopause, consuming vitamin D-interfering drugs (corticosteroids, antiepileptics and contraceptives) and also calcium and vitamin D supplementation in last six months, no history of myocardial infarction, angina pectina and stroke in last year or suffering from cardiovascular, liver, kidney, thyroid gland diseases and chronic inflammation. Exclusion criteria were non-regular consumption of supplements (consuming less than $80 \%$ ), changes in the dietary intake, physical activity level and medications.

Participants were explained in regard to the protocol and the aim of the study and the written informed consent was obtained. A demographic questionnaire was completed for each patient and blood samples were collected for determining the concentrations of serum 25-hydroxyvitamin D. Then, vitamin D-insufficient or deficient diagnosed patients were randomly stratified according to sex into two groups receiving 50000 IU/week vitamin $\mathrm{D}$, or paraffin as placebo.

\subsection{Intervention}

Current acceptable approaches to treat vitamin D deficiency in infants are $2000 \mathrm{IU} / \mathrm{d}$ or a single dose of 50000 IU/week for 6 weeks until the serum 25-hydoryvitamin D level gets above $30 \mathrm{ng} / \mathrm{mL}$ and then 400-1000 IU/d for maintenance. In children 1-18 years old, treatments are $2000 \mathrm{IU} / \mathrm{d}$ at least for 6 weeks or a single dose of 50000 IU/week at least for 6 weeks and the maintenance of 600$1000 \mathrm{IU} / \mathrm{d}$. In all adults the recommended approach is a single dose of $50000 \mathrm{IU} /$ week for 8 weeks to reach above $30 \mathrm{ng} / \mathrm{mL}$ and the maintenance dose of 1500-2000IU/d. In obesity, malabsorption syndrome or taking drugs affecting vitamin D metabolism, higher doses (6000-10000 $\mathrm{IU} / \mathrm{d})$ are recommended and the maintaining dose would be 3000-6000 IU/d (31).

Vitamin D supplementation in this study was 50000IU vitamin D3 soft gelatin spherical pearls with clear and transparent shell. Placebo contained paraffin and were as similar as vitamin D pearls in appearance. All supplements were supplied by Zahravi, Iran. Vitamin D and placebo batches were named as A or B by a third person. Each volunteers received eight pearls (vitamin $D$ or placebo) in one batch at the beginning of the study and were asked to take weekly for eight weeks.

All participants were recommended not to change their usual physical activity level and food intakes. Maintaining the medication as before was a criteria for continuing the study. At the end of the study, compliance rate of the patients was evaluated through counting the remaining capsules. 


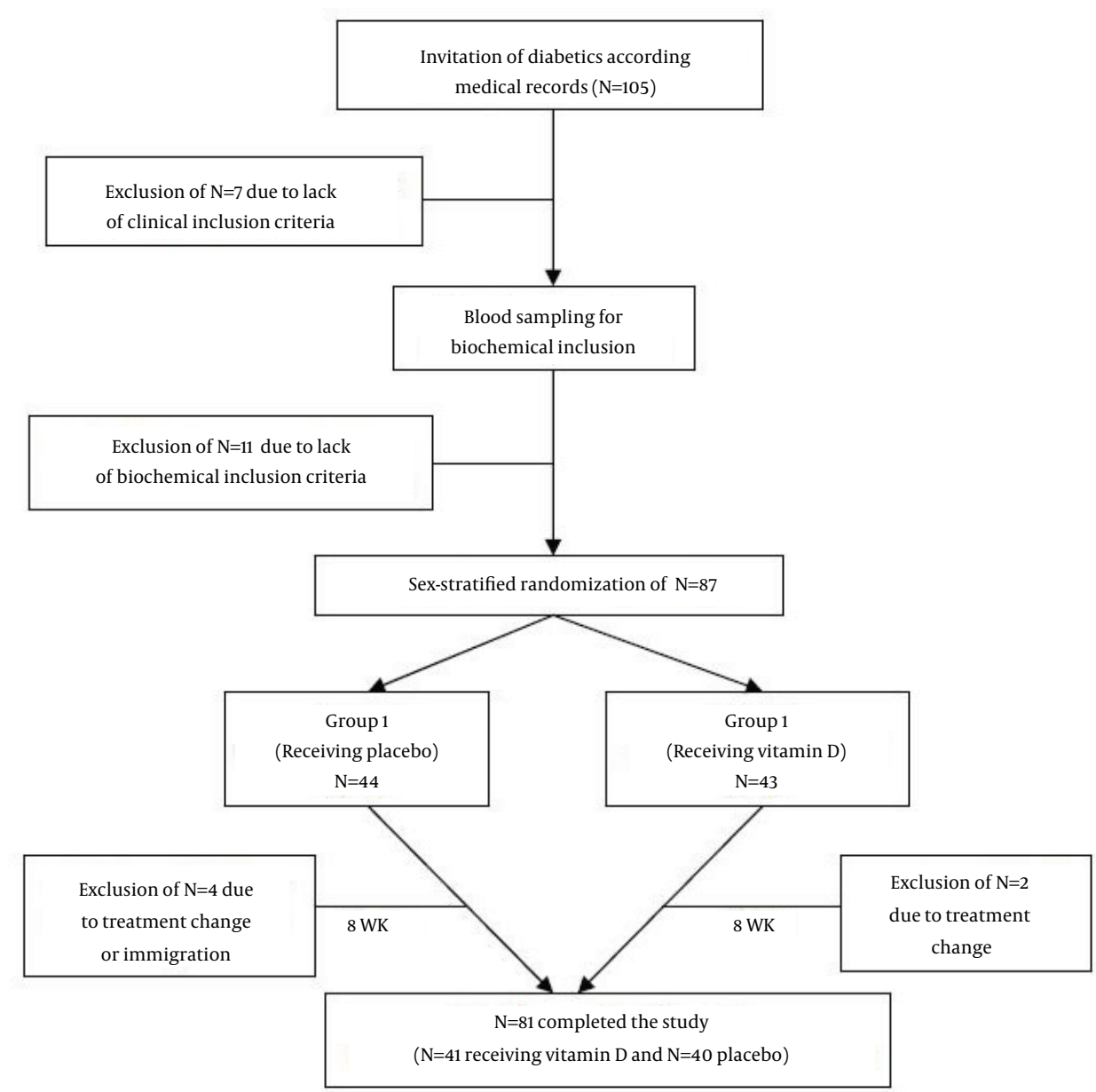

Figure 1. Flow Chart of the Study

\subsection{Anthropometric Measurements and Physical Activity Level}

Height was measured with a wall-mounted stadiometer to the nearest $0.1 \mathrm{~cm}$. Weight was determined to the nearest $0.1 \mathrm{~kg}$ on the same properly calibrated electronic digital scale, without shoes, with minimal clothing, and after voiding. Two measurements were obtained and averaged; with a third measurement taken if the first two differed by 0.1. Body mass index (BMI) was estimated as the ratio of body weight to height squared and expressed as $\mathrm{kg} / \mathrm{m}^{2}$. Physical activity level was assessed by a validated questionnaire in which nine different metabolic equivalent (MET) levels were ranged on a scale from sleep/rest (0.9 METs) to high-intensity physical activities (> 6 METs).

\subsection{Dietary Intake}

Dietary intake of vitamin D and calcium were ensured through 1-day 24-hour dietary recall at the baseline and end of the eighth week of the study. This dietary information was analyzed with N4 software (Nutritionist: version 4.0; Tinuviel Software, Warrington, United Kingdom).

\subsection{Biochemical Data Assessment}

Seven ml 12-hour fasting state blood samples were collected from brachial vein at the baseline and end of study. The samples centrifuged immediately at $3000 \mathrm{rpm}$ for 15 minutes and promptly the serum aliquoted into separate tubes. Aliquoted samples were stored at $-70^{\circ} \mathrm{C}$ until analysis. One $\mathrm{mL}$ whole blood samples were stored to measure HbA1c.

Serum glucose concentration was measured (Glucose determination kit, Parsazmun, Tehran, Iran) through auto-analyzer instrument (Sellectra II, Dieren, Netherland) and fluorometric method according glucose oxidase principle. Serum insulin was measured by enzymelinked immunosorbent assay (ELISA) kit (Monobind, Uppsala, US). Homeostasis model of assessment (HOMAIR) as an index of insulin resistance was used (32). Glycated hemoglobin was determined in whole blood sample by DS5 chromatography method (HbA1c Kit, Drew Scientific Limited, Villaricca, United Kingdom). The intra- and inter- assay coefficients of variation (CVs) for glucose, insulin and HbA1c were 4.7\%, 5.5\%, 5.6\% and 4.9\%, 5.8\%, 5.8\%, respectively. The sensitivity of the assays for glucose, in- 
Baziar N et al.

sulin and HbA1c were $1 \mathrm{mg} / \mathrm{dL}, 1 \mathrm{mU} / \mathrm{L}$ and $1 \%$, respectively. Serum 25-hydroxyvitamin D was measured using ELISA (IDS, Boldon, UK). The intra- and inter-assay CVs for serum vitamin D were $5.4 \%$ and 5.5\%, respectively. The sensitivity of the assays was $5 \mathrm{nmol} / \mathrm{L}$. Serum adiponectin were also measured by ELISA kit (Mediagnost, Uppsala, Germany). The intra-and inter- assay CVs for adiponectin were 1.5\% and $2 \%$, respectively. The sensitivity of the assays was 0.6 $\mathrm{ng} / \mathrm{mL}$.

\subsection{Statistical Analysis}

Data were analyzed with statistical package software for social sciences, version 16 (SPSS Inc. Chicago, IL, USA). Kolmogrov-Smirinov test was used to show the normality and homogeneity of variances. Paired t-test was used to compare the mean variables before and after the intervention in each group. T-test was used to compare the mean differences of variables before and after the intervention as well as the mean changes between the groups. An alpha level of less than 0.05 was accepted in all tests as statistically significant and with the sample size of 87 ; a power value of $\% 90$ was generated. This study was submitted in Iranian Registry of Clinical Trials as IRCT2013052111421N2.

\section{Results}

Among 87 patients, two patients receiving placebo and two cases in vitamin D receiving groups were excluded from the study due to the changes in diabetes treatment procedure and one placebo as immigration. At the end, 82 patients completed the study. Baseline characteristics of the patients listed in Table 1 . There were no significant differences in baseline characteristics between the groups. A statistical, but not clinical significant difference with higher level in the placebo group was shown in HbA1c (P value $=0.048$ )

As seen in Table 2, there was no significant difference in baseline serum 25-hydroxyvitamin D concentration between the two groups. After eight-week intervention, serum 25-hydroxyvitamin D increased significantly in the group receiving vitamin $\mathrm{D}(\mathrm{P}$ value $<0.001)$. The lowest and highest of achieved 25-hydroxyvitamin D concentration in the intervention group were 29.2 and $88 \mathrm{~g} / \mathrm{mL}$, respectively. Comparing difference in changes between the two groups showed that vitamin D increased serum 25-hydroxyvitamin D by about 200 percent (P value < 0.001).

The means and standard deviation of fasting serum glucose, insulin and HOMA-IR at the beginning and end of the study and their changes in each group were presented in Table 3. In patients taking vitamin, fasting glucose concentration decreased significantly in comparison to the beginning $(\mathrm{P}$ value $=0.045)$ and also to placebo $(\mathrm{P}$ value $=0.014)$. Fasting serum insulin was decreased significantly in the intervention group (P value $=0.028$ ). Comparison of the mean changes of serum insulin in the two groups showed a significant change in the group receiving vitamin $\mathrm{D}(\mathrm{P}$ value $=0.048)$. Vitamin $\mathrm{D}$ significantly decreased insulin resistance $(P$ value $=0.007)$ and the mean decrease in insulin resistance in patients receiving vitamin D was significantly higher than those who received placebo (Pvalue $=0.006)$.

The means and standard deviation of serum adiponectin and its change in each group at the beginning and end of study were presented in Table 3. At the end of the study, no significant changes were seen in adiponectin concentrations in neither vitamin $\mathrm{D}$ nor placebo

Table 1. Baseline Demographic Characteristics of Patients ${ }^{a}$

\begin{tabular}{|c|c|c|c|}
\hline Variables & Vitamin D & Placebo & PValue $^{b}$ \\
\hline \multicolumn{4}{|l|}{ Gender, No. } \\
\hline Male & 28 & 26 & 0.07 \\
\hline Female & 13 & 14 & \\
\hline Age, y & $50.34 \pm 6.71$ & $52.75 \pm 6.34$ & 0.11 \\
\hline Diabetes duration, y & $5.44 \pm 2.90$ & $6.43 \pm 2.97$ & 0.15 \\
\hline BMI, $\mathrm{kg} / \mathrm{m}^{2}$ & $27.33 \pm 1.64$ & $27.25 \pm 1.35$ & 0.83 \\
\hline HbA1c, \% & $6.49 \pm 0.74$ & $6.94 \pm 1.16$ & 0.04 \\
\hline $25(\mathrm{OH})$ vitamin $\mathrm{D}, \mathrm{ng} / \mathrm{mL}$ & $14.33 \pm 5.85$ & $15.50 \pm 5.55$ & 0.37 \\
\hline FBS, mg/dL & $150 \pm 51$ & $134 \pm 36$ & 0.40 \\
\hline $\begin{array}{l}\text { Fasting serum insulin, } \\
\mathrm{mU} / \mathrm{L}\end{array}$ & $7.78 \pm 5.98$ & $8.23 \pm 5.76$ & 0.75 \\
\hline HOMA-IR ${ }^{\mathrm{C}}$ & $2.84 \pm 2.61$ & $2.74 \pm 1.95$ & 0.87 \\
\hline Serum adiponectin, $\mu \mathrm{g} / \mathrm{mL}$ & $3.48 \pm 1.57$ & $4.04 \pm 3.98$ & 0.05 \\
\hline PAL, MET & $1.45 \pm 0.21$ & $1.47 \pm 0.27$ & 0.51 \\
\hline Calorie intake, Kcal & $2135 \pm 211$ & $2126 \pm 250$ & 0.76 \\
\hline Protein intake, $g$ & $85 \pm 20$ & $83 \pm 22$ & 0.56 \\
\hline $\begin{array}{l}\text { Carbohydrate intake, } \% \text { of } \\
\text { calorie }\end{array}$ & $60 \pm 4$ & $59 \pm 5$ & 0.76 \\
\hline Fat intake, \% of calorie & $26 \pm 3$ & $25 \pm 3$ & 0.65 \\
\hline
\end{tabular}

a Abbreviations: BMI; body mass index, HbA1c; hemoglobin A1c, FBS; fasting blood glucose, HOMA-IR; homeostatic model assessment of insulin resistance, PAL; (MET) physical activity level (metabolic equivalent).

b P Value of chi square and independent t-test for variable sex and others, respectively.

c HOMA-IR Homeostatic Model Assessment-Insulin Resistance.

Table 2. Mean and Standard Deviation of 25-Hydroxyvitamin D Before and After Eight-week Vitamin D Supplementation

\begin{tabular}{lllc}
\hline $\begin{array}{l}\text { Serum 25 } \\
(\mathrm{OH}) \mathrm{D}, \mathrm{ng} /\end{array}$ & $\mathrm{T}=\mathbf{0}$ & $\mathrm{T}=\mathbf{8}$ wk & $\begin{array}{c}\text { Mean } \\
\text { change }\end{array}$ \\
mL
\end{tabular}

Vitamin D (n $14.33 \pm 5.85 \quad 45.03 \pm 12.60 \quad 30.70 \pm 13.73<0.001$ $=41$ )

\begin{tabular}{lcccc}
$\begin{array}{l}\text { Placebo }(\mathbf{n}= \\
\text { 40 })\end{array}$ & $15.50 \pm 5.55$ & $16.85 \pm 6.25$ & $1.35 \pm 3.59$ & 0.028 \\
P Value $^{\mathrm{b}}$ & 0.378 & $<0.001$ & $<0.001$ & \\
\hline
\end{tabular}

a $P$ value of paired t-test.

$\mathrm{b}$ P value of independent t-test. 
BaziarN et al.

Table 3. Mean and Standard Deviation of Glycemic Indicators and Adiponectin Before and After Eight-week Vitamin D Supplementation in Vitamin $\mathrm{D}(\mathrm{n}=41)$ and Placebo $(\mathrm{n}=40)$ Groups

\begin{tabular}{|c|c|c|c|c|}
\hline Variables & $\mathbf{T}=\mathbf{0}$ & $\mathbf{T}=\mathbf{8} \mathbf{w k}$ & Mean change & PValue $^{\mathrm{a}}$ \\
\hline \multicolumn{5}{|c|}{ Fasting serum glucose, $\mathrm{mg} / \mathrm{dL}$} \\
\hline Vitamin D & $150.29 \pm 51.37$ & $135.23 \pm 37.67$ & $-15.05 \pm 42.05$ & 0.045 \\
\hline Placebo & $134.74 \pm 36.50$ & $143.80 \pm 46.29$ & $9.06 \pm 33.57$ & 0.143 \\
\hline Pvalue $^{\mathrm{b}}$ & 0.409 & 0.162 & 0.014 & \\
\hline \multicolumn{5}{|c|}{ Fasting serum insulin, mU/L } \\
\hline Vitamin D & $7.78 \pm 5.98$ & $5.68 \pm 4.06$ & $-2.09 \pm 5.30$ & 0.028 \\
\hline Placebo & $8.23 \pm 5.76$ & $8.57 \pm 6.82$ & $0.33 \pm 4.31$ & 0.668 \\
\hline Pvalue $^{b}$ & 0.757 & 0.040 & 0.048 & \\
\hline \multicolumn{5}{|l|}{ HOMA-IR ${ }^{\mathrm{C}}$} \\
\hline Vitamin D & $2.84 \pm 2.61$ & $1.84 \pm 1.18$ & $-1.00 \pm 2.05$ & 0.007 \\
\hline Placebo & $2.74 \pm 1.95$ & $3.17 \pm 2.84$ & $0.42 \pm 1.69$ & 0.212 \\
\hline Pvalue ${ }^{b}$ & 0.872 & 0.032 & 0.006 & \\
\hline \multicolumn{5}{|c|}{ Serum adiponectin, $\mu \mathrm{g} / \mathrm{mL}$} \\
\hline Vitamin D & $3.48 \pm 1.57$ & $3.73 \pm 2.00$ & $0.25 \pm 1.05$ & 0.186 \\
\hline Placebo & $4.04 \pm 3.98$ & $4.22 \pm 4.99$ & $0.18 \pm 1.81$ & 0.600 \\
\hline Pvalue $^{\mathrm{b}}$ & 0.054 & 0.132 & 0.831 & \\
\hline
\end{tabular}

groups ( $\mathrm{P}$ value $=0.186$ and 0.60 , respectively). Also, the mean changes were not significantly different between the groups $($ P value $=0.831)$.

\section{Discussion}

In this study, eight weeks of $50000 \mathrm{IU} /$ week vitamin D administration increased serum 25-hydroxyvitamin D and decreased fasting serum glucose, insulin and also insulin resistance with no changes in serum adiponectin. At the end of the study, the lowest concentration of 25-hydroxyvitamin D in the intervention group was 29.2 $\mathrm{ng} / \mathrm{mL}$, which was close to the defined normal range (31$40 \mathrm{ng} / \mathrm{mL}$ ). Also, the highest achieved level was $88 \mathrm{ng} /$ $\mathrm{mL}$ compared to the toxicity level of $150 \mathrm{ng} / \mathrm{mL}$. These showed the effectiveness and safety of therapeutic dose of vitamin D in improving vitamin D status.

A significant association have been reported between serum 25-hydoxyvitamin D and glycemic control in crosssectional studies $(5,33,34)$, while interventional studies reported contradictory results on glycemia or other glycemic indicators, which may be as a result of disparities in study design, supplementation dosage and possibly baseline concentration of 25-hydroxyvitamin D (6, 35, 36). In almost all studies reported to date on vitamin Dinsufficient or deficient subjects, vitamin D supplementation increased serum 25-hydroxyvitamin D to the normal range and subsequently decreased insulin resistance $(6,25,37-40)$. But, some other studies did not show any effects on glycemia $(10,28,35,41)$. Witham et al. (41) did not show any significant improvement in insulin resistance after 16 months of receiving a single dose (100000 and 200000 IU) of vitamin D. Although, a significant decrease in insulin resistance was reported after eight- week 2000000 IU vitamin D supplementation, this effect was less following a decrease in serum 25-hydroxyvoitamin D. Moreover, Jorde et al. did not report any beneficial effect of six-month $4000 \mathrm{IU} /$ week supplementation on glycemic indicators in diabetic patients; however, baseline vitamin D status of the participants was higher than $20 \mathrm{ng} /$ $\mathrm{mL}$ (35). Breslavsky et al. also failed to bring serum 25-hydroxyvitamin $\mathrm{D}$ to the normal levels despite 12- month 1000 IU/day vitamin supplementation; which was justified by the progressive nature of diabetes (10). Patel et al . also failed to achieve normal vitamin D status and reveal any benefits for vitamin D supplementation on glycemic control. Their study was not a placebo-controlled (28). Nagpal et al. reported an improvement in oral glucose insulin sensitivity (OGIS) in individuals with abdominal obesity along with no achievement of normal serum vitamin $\mathrm{D}$ or improvement in other insulin sensitivity indicators or HOMA-IR (36). HOMA-IR is according to fasting plasma glucose and insulin concentration and is an indicator of measuring liver resistance against insulin in producing and releasing glucose, while OGIS measures the ability of insulin in stimulating muscles to uptake 2-hour postprandial blood glucose (36). Neglecting OGIS may be considered as a limitation of our study; because both HOMA-IR and OGIS calculation may be essential to 
determine the exact effects of vitamin D supplementation on insulin sensitivity and glycemia. It is possible that a single high dose injection of vitamin $\mathrm{D}$, not only has no beneficial effects on insulin resistance, but also may have adverse effects on glycemic indicators (38). Taylor and colleagues reported increasing in insulin resistance and worsening glycemia in three type 2 diabetic patients with vitamin $D$ deficiency three months following the injection of $300000 \mathrm{IU}$ vitamin $\mathrm{D}$; however, significant increases were shown in serum 25-hydroxy vitamin D, but none of three-mentioned patients achieved normal levels (42). Furthermore, Heshmat et al. conducted a similar study and failed to show any improvement of glycemic indicators. Even a non-significant incensement was seen in subjects taking vitamin $\mathrm{D}(3.1 \pm 2.3$ to $3.4 \pm 1.9)$ (30). It seems that an injection of vitamin D (a single dose) increased serum 25-hydroxyvitamin D for a short-term; so, measuring the glycemic indicators three months after injection could be affected by other confounders. Furthermore, baseline status $(46.92 \pm 34.7 \mathrm{ng} / \mathrm{mL})$ was in normal range. Totally, it appears that vitamin D supplementation improves glycemia in vitamin D-insufficient or deficient patients providing improvement of vitamin status.

Several vitamin D and diabetes linking mechanisms have been suggested including the effects of vitamin $\mathrm{D}$ on insulin secretion, peripheral insulin resistance and inflammation. 1,25-dihydroxyvitamin D bind to nuclear receptors and up-regulate insulin cell-membrane receptors, increases the receptor synthesis resulting more presence of insulin-dependent glucose transporter (GLUT4) in cell membrane (43). Vitamin D also up-regulates peroxisome proliferator-activated receptors, which improve fatty acid metabolism and insulin sensitivity (44). It was also reported that vitamin $\mathrm{D}$ regulates renin-angiotensin system through down-regulating renin and inhibiting angiotensin-I receptors, which their activity involves in insulin resistance, inflammation and hypertension (45). Another suggested mechanism is an increasing of parathyroid hormone and subsequently lipogenesis, obesity and insulin resistance due to vitamin deficiency (46).

Despite the reported associations between vitamin D status and serum adiponectin as a cause of insulin resistance in individuals $(7,11,25)$, in the present study, vitamin $D$ therapeutic dose had no effect on improving serum adiponectin. This finding is similar to the study by Breslavsky (1000 IU/day vitamin D for 12 months) (10) and Patel et al. (400 IU and $1200 \mathrm{IU} /$ day for 4 months) (28). However, in the first study, normal serum vitamin D levels did not achieve (10) and in the second, low sample size and absence of control group was prompted less power (28).

Several mechanisms have been suggested to express the potential effects of vitamin D on adiponectin. Vitamin D may affect adiponectin through renin-angiotensinogen system. Increased activity of renin-angiotensinogen system is associated with an increased angiotensin production, which leads to the production of dysfunctional adipocytes and finally, decreased adiponectin production.
Vitamin D may involve in increasing serum adiponectin by down-regulating and decreasing angiotensin production $(11,21)$. Insulin resistance and glucose intolerance are inflammatory conditions that are associated with decreased production of adiponectin and increased activity of inflammatory cytokines as well as TNF- $\alpha$ and interleukin-1. TNF- $\alpha$ reduces adiponectin synthesis and vitamin D may be associated with increased serum adiponectin through decreasing gene expression (5). With vitamin D receptors on adipocytes, direct involvement of vitamin $\mathrm{D}$ in adiponectin gene expression is considered (5). Vitamin D and calcium may play a role in the regulation adipocytokine gene expression in visceral adipose tissue. Another mechanism explaining the association between vitamin $\mathrm{D}$ and adiponectin is osteocalcin. Vitamin $\mathrm{D}$ is associated with the up-regulating of osteocalcin, which its carboxylated form plays a role in energy and glucose homeostasis (7). Adding osteocalcin into adipocyte cell cultures increased an adiponectin gene expression (7). Despite aforementioned mechanisms, in the present study, although serum vitamin $D$ reached to normal levels and led to improvement in insulin resistance, no statistical significant changes were shown in serum adiponectin concentration. It should be noted that two forms of circulating adiponectin are found; low-molecular weight (LMW) and high-molecular weight (HMW) adiponectin. The second is active form and the ratio of HMW adiponectin to total is more accurate in assessment of the association between insulin resistance and adiponectin (47). So, the measurement of only total adiponectin level could be a big limitation of our study. Indeed, further studies recommended to investigate the effects of vitamin $D$ on different forms of serum adiponectin. Another weakness of this study was the biochemical assessments immediately at the end of the study. It appears likely there was not enough time for revealing the positive effects of vitamin $\mathrm{D}$ on adiponectin gene expression or other possible mechanisms. So, it could not be definitely assigned vitamin $\mathrm{D}$ as no effect on adiponectin. The strong point of this study was the inclusion of vitamin D-insufficient or deficient type 2 diabetic patients with a narrow range of 25-hydroxyvitamin D concentrations that may be the most predictive value in interpreting of the results but has been ignored in previews studies.

In summary, therapeutic dose of vitamin D (50000 IU) week) for 8 weeks in vitamin D- insufficient or deficient type 2 diabetic patients improves the low levels of vitamin D status and glycemia, with no positive effect on serum adiponectin. A routine control of vitamin $D$ status in type 2 diabetic patients and treatment of deficiency is suggested in vitamin D-insufficient patients to achieve a better control of glycemia.

\section{Acknowledgements}

This study was supported by a research grant from Diabetes Research Center, Endocrinology and Metabolism Research Center, Tehran University of Medical Sciences. 
We are indebted to kind collaboration of several endocrinology specialists. We thank Dr. Razi who provided and coordinated biochemical analysis on behalf of laboratory of endocrine and metabolism research center and express our gratitude to the staffs of laboratory at diabetes clinic for their skillful technical assistance.

\section{Authors' Contributions}

Nima Baziar conceived of the study, carried out the designe of the article, coordinated the implementation, drafted the manuscript, and performed the statistical analysis. Kurosh Jafarian participated in the design of the study and revised the manuscript. Zhaleh Shadman conceived the study, carried out its designing, coordinated the implementation, drafted the manuscript, and performed the statistical analysis. Mostafa Qorbani participated in analysis and interpretation of data and revised the manuscript. Mohsen khoshniat participated in the design of the study and revised the manuscript. Mahshid Abd Mishani participated in acquisition of data and revised the manuscript. The authors thank all who participated in or collaborated with the present study.

\section{Funding/Support}

This study was supported in part by grant E-00180 from the Endocrinology and Metabolism Research Institute of Tehran University of Medical Sciences.

\section{References}

1. Alvarez JA, Ashraf A. Role of vitamin d in insulin secretion and insulin sensitivity for glucose homeostasis. Int $J$ Endocrinol. 2010;2010:351385.

2. Forouhi NG, Luan J, Cooper A, Boucher BJ, Wareham NJ. Baseline serum 25-hydroxy vitamin d is predictive of future glycemic status and insulin resistance: the Medical Research Council Ely Prospective Study 1990-2000. Diabetes. 2008;57(10):2619-25.

3. Chiu KC, Chu A, Go VL, Saad MF. Hypovitaminosis D is associated with insulin resistance and beta cell dysfunction. Am J Clin Nutr. 2004;79(5):820-5.

4. Sung CC, Liao MT, Lu KC, Wu CC. Role of vitamin D in insulin resistance. J Biomed Biotechnol. 2012;2012:634195.

5. Liu E, Meigs JB, Pittas AG, McKeown NM, Economos CD, Booth SL, et al. Plasma 25-hydroxyvitamin d is associated with markers of the insulin resistant phenotype in nondiabetic adults. J Nutr. 2009;139(2):329-34.

6. Borissova AM, Tankova T, Kirilov G, Dakovska L, Kovacheva R. The effect of vitamin D3 on insulin secretion and peripheral insulin sensitivity in type 2 diabetic patients. Int J Clin Pract. 2003;57(4):258-61.

7. Nimitphong $\mathrm{H}$, Chanprasertyothin S, Jongjaroenprasert W, Ongphiphadhanakul B. The association between vitamin D status and circulating adiponectin independent of adiposity in subjects with abnormal glucose tolerance. Endocrine. 2009;36(2):205-10.

8. Scragg R, Sowers M, Bell C, Third National H, Nutrition Examination S. Serum 25-hydroxyvitamin D, diabetes, and ethnicity in the Third National Health and Nutrition Examination Survey. Diabetes Care. 2004;27(12):2813-8.

9. Roth CL, Elfers C, Kratz M, Hoofnagle AN. Vitamin d deficiency in obese children and its relationship to insulin resistance and adipokines. J Obes. 2011;2011:495101.

10. Breslavsky A, Frand J, Matas Z, Boaz M, Barnea Z, Shargorodsky M. Effect of high doses of vitamin D on arterial properties, adi- ponectin, leptin and glucose homeostasis in type 2 diabetic patients. Clin Nutr. 2013;32(6):970-5.

11. Vaidya A, Forman JP, Underwood PC, Hopkins PN, Williams GH, Pojoga LH, et al. The influence of body mass index and reninangiotensin-aldosterone system activity on the relationship between 25-hydroxyvitamin D and adiponectin in Caucasian men. Eur Endocrinol. 2011;164(6):995-1002.

12. Hivert MF, Sullivan LM, Shrader P, Fox CS, Nathan DM, D'Agostino $\mathrm{BR}$, et al. Insulin resistance influences the association of adiponectin levels with diabetes incidence in two population-based cohorts: the Cooperative Health Research in the Region of Augsburg (KORA) S4/F4 study and the Framingham Offspring Study. Diabetologia. 2011;54(5):1019-24.

13. Jalovaara K, Santaniemi M, Timonen M, Jokelainen J, Kesaniemi YA, Ukkola O, et al. Low serum adiponectin level as a predictor of impaired glucose regulation and type 2 diabetes mellitus in a middle-aged Finnish population. Metabolism. 2008;57(8):1130-4.

14. Luo M, Oza-Frank R, Narayan KM, Gokulakrishnan K, Mohan V. Serum total adiponectin is associated with impaired glucose tolerance in Asian Indian females but not in males.J Diabetes Sci Technol. 2010;4(3):645-51.

15. Peters KE, Beilby J, Cadby G, Warrington NM, Bruce DG, Davis WA, et al. A comprehensive investigation of variants in genes encoding adiponectin (ADIPOQ) and its receptors (ADIPOR1/R2), and their association with serum adiponectin, type 2 diabetes, insulin resistance and the metabolic syndrome. BMC Med Genet. 2013;14:15.

16. Swarbrick MM, Havel PJ. Physiological, pharmacological, and nutritional regulation of circulating adiponectin concentrations in humans. Metab Syndr Relat Disord. 2008;6(2):87-102.

17. Dastani Z, Hivert MF, Timpson N, Perry JR, Yuan X, Scott RA, et al. Novel loci for adiponectin levels and their influence on type 2 diabetes and metabolic traits: a multi-ethnic meta-analysis of 45,891 individuals. PLoS Genet. 2012;8(3): e1002607.

18. Tabak AG, Brunner EJ, Miller MA, Karanam S, McTernan PG, Cappuccio FP, et al. Low serum adiponectin predicts 10-year risk of type 2 diabetes and HbA1c independently of obesity, lipids, and inflammation: Whitehall II study. Horm Metab Res. 2009;41(8):626-9.

19. Kawano J, Arora R. The role of adiponectin in obesity, diabetes, and cardiovascular disease. J Cardiometab Syndr. 2009;4(1):44-9.

20. Mather KJ, Funahashi T, Matsuzawa Y, Edelstein S, Bray GA, Kahn $\mathrm{SE}$, et al. Adiponectin, change in adiponectin, and progression to diabetes in the Diabetes Prevention Program. Diabetes. 2008;57(4):980-6.

21. Vaidya A, Williams JS, Forman JP. The independent association between 25-hydroxyvitamin D and adiponectin and its relation with BMI in two large cohorts: the NHS and the HPFS. Obesity (Silver Spring). 2012;20(1):186-91.

22. Fagerberg B, Kellis D, Bergstrom G, Behre CJ. Adiponectin in relation to insulin sensitivity and insulin secretion in the development of type 2 diabetes: a prospective study in 64-year-old women. J Intern Med. 2011;269(6):636-43.

23. Ashwal R, Hemi R, Tirosh A, Gordin R, Yissachar E, Cohen-Dayag A, et al. Differential expression of novel adiponectin receptor-1 transcripts in skeletal muscle of subjects with normal glucose tolerance and type 2 diabetes. Diabetes. 2011;60(3):936-46.

24. Gannage-Yared MH, Chedid R, Khalife S, Azzi E, Zoghbi F, Halaby G. Vitamin D in relation to metabolic risk factors, insulin sensitivity and adiponectin in a young Middle-Eastern population. EurJ Endocrinol. 2009;160(6):965-71.

25. Al-Daghri NM, Al-Attas OS, Alokail MS, Alkharfy KM, Al-Othman A, Draz HM, et al. Hypovitaminosis D associations with adverse metabolic parameters are accentuated in patients with Type 2 diabetes mellitus: a body mass index-independent role of adiponectin? J Endocrinol Invest. 2013;36(1):1-6.

26. Krans HM. Baseline serum 25-hydroxy vitamin D in predicting glycemic status and insulin levels. F1000 Med Rep. 2009;1.

27. Pittas AG, Sun Q, Manson JE, Dawson-Hughes B, Hu FB. Plasma 25-hydroxyvitamin D concentration and risk of incident type 2 diabetes in women. Diabetes Care. 2010;33(9):2021-3.

28. Patel P, Poretsky L, Liao E. Lack of effect of subtherapeutic vitamin D treatment on glycemic and lipid parameters in Type 2 diabetes: 
A pilot prospective randomized trial. J Diabetes. 2010;2(1):36-40.

29. Esteghamati A, Gouya MM, Abbasi M, Delavari A, Alikhani S, Alaedini F, et al. Prevalence of diabetes and impaired fasting glucose in the adult population of Iran: National Survey of Risk Factors for Non-Communicable Diseases of Iran. Diabetes Care. 2008;31(1):96-8.

30. Heshmat R, Tabatabaei-Malazy O, Abbaszadeh-Ahranjani S, Shahbazi S, Khooshehchin G, Bandarian F, et al. Effect of vitamin D on insulin resistance and anthropometric parameters in Type 2 diabetes; a randomized double-blind clinical trial. Daru. 2012;20(1):10.

31. Holick MF. Vitamin D deficiency. N Engl J Med. 2007;357(3):266-81.

32. Matthews DR, Hosker JP, Rudenski AS, Naylor BA, Treacher DF, Turner RC. Homeostasis model assessment: insulin resistance and beta-cell function from fasting plasma glucose and insulin concentrations in man. Diabetologia. 1985;28(7):412-9.

33. Al-Daghri NM, Alkharfy KM, Al-Saleh Y, Al-Attas OS, Alokail MS, AlOthman A, et al. Modest reversal of metabolic syndrome manifestations with vitamin D status correction: a 12-month prospective study. Metabolism. 2012;61(5):661-6.

34. Reis JP, von Muhlen D, Miller E3, Michos ED, Appel LJ. Vitamin D status and cardiometabolic risk factors in the United States adolescent population. Pediatrics. 2009;124(3):e371-9.

35. Jorde R, Figenschau Y. Supplementation with cholecalciferol does not improve glycaemic control in diabetic subjects with normal serum 25-hydroxyvitamin D levels. Eur J Nutr. 2009;48(6):349-54.

36. Nagpal J, Pande JN, Bhartia A. A double-blind, randomized, placebo-controlled trial of the short-term effect of vitamin D3 supplementation on insulin sensitivity in apparently healthy, middleaged, centrally obese men. Diabet Med. 2009;26(1):19-27.

37. Selimoglu H, Duran C, Kiyici S, Ersoy C, Guclu M, Ozkaya G, et al. The effect of vitamin D replacement therapy on insulin resistance and androgen levels in women with polycystic ovary syndrome. J Endocrinol Invest. 2010;33(4):234-8.

38. von Hurst PR, Stonehouse W, Coad J.Vitamin D supplementation reduces insulin resistance in South Asian women living in New Zealand who are insulin resistant and vitamin D deficient - a randomised, placebo-controlled trial. BrJ Nutr. 2010;103(4):549-55.

39. Talaei A, Mohamadi M, Adgi Z. The effect of vitamin D on insulin resistance in patients with type 2 diabetes. Diabetol Metab Syndr. 2013;5(1):8.

40. Belenchia AM, Tosh AK, Hillman LS, Peterson CA. Correcting vitamin D insufficiency improves insulin sensitivity in obese adolescents: a randomized controlled trial. Am J Clin Nutr. 2013;97(4):774-81.

41. Witham MD, Dove FJ, Dryburgh M, Sugden JA, Morris AD, Struthers AD. The effect of different doses of vitamin $\mathrm{D}(3)$ on markers of vascular health in patients with type 2 diabetes: a randomised controlled trial. Diabetologia. 2010;53(10):2112-9.

42. Taylor AV, Wise PH. Vitamin D replacement in Asians with diabetes may increase insulin resistance. Postgrad Med J. 1998;74(872):365-6.

43. Maestro B, Campion J, Davila N, Calle C. Stimulation by 1,25-dihydroxyvitamin D3 of insulin receptor expression and insulin responsiveness for glucose transport in U-937 human promonocytic cells. EndocrJ. 2000;47(4):383-91.

44. Sertznig P, Seifert M, Tilgen W, Reichrath J. Peroxisome proliferator-activated receptor (PPAR) and vitamin D receptor (VDR) signaling pathways in melanoma cells: promising new therapeutic targets? J Steroid Biochem Mol Biol. 2010;121(1-2):383-6.

45. Reusch JE, Begum N, Sussman KE, Draznin B. Regulation of GLUT4 phosphorylation by intracellular calcium in adipocytes. Endocrinology. 1991;129(6):3269-73.

46. Reis JP, von Muhlen D, Kritz-Silverstein D, Wingard DL, BarrettConnor E. Vitamin D, parathyroid hormone levels, and the prevalence of metabolic syndrome in community-dwelling older adults. Diabetes Care. 2007;30(6):1549-55.

47. Lihn AS, Pedersen SB, Richelsen B. Adiponectin: action, regulation and association to insulin sensitivity. Obes Rev. 2005;6(1):13-21. 